九州大学学術情報リポジトリ

Kyushu University Institutional Repository

The Importance of Food and Host on the

Fecundity and Longevity of a Host-feeding

Parasitoid Wasp

Liu, Hongyue

Institute of Biological Control, Bioresource Sciences, Bioresource Sciences, Kyushu University

Ueno, Takatoshi

Institute of Biological Control, Bioresource Sciences, Bioresource Sciences, Kyushu University

https://doi.org/10.5109/22058

出版情報: 九州大学大学院農学研究院紀要. 57 (1)，pp.121-125，2012-02. Faculty of Agriculture， Kyushu University

バージョン :

権利関係 : 


\title{
The Importance of Food and Host on the Fecundity and Longevity of a Host-feeding Parasitoid Wasp
}

\author{
Hongyue LIU and Takatoshi UENO* \\ Laboratory of Insect Natural Enemies, Division of Biological Control, Department of Applied Genetics and \\ Pest Management, Graduate School of Bioresource and Bioenvironmental Sciences, \\ Faculty of Agriculture, Kyushu University, Fukuoka 812-8581, Japan \\ (Received October 31, 2011 and accepted November 9, 2011)
}

\begin{abstract}
Trade-off among life-history traits has been a central subject in the research of evolutionary ecology and biology. A major trade-off concerned is found in the relationship between reproduction and life expectancy but the trade-off between the two may depend on the environment such as food availability. In parasitoids, cost of reproduction has been examined only for a few species. The solitary pupal parasitoid wasp Itoplectis naranyae (Hymenoptera: Ichneumonidae) is a typical host-feeder, and host-feeding in this parasitoid is known to relate to egg production. Here, we first examined whether cost of reproduction occurs in I. naranyae by comparing the longevity between females with and without host provision. Because $I$. naranyae use hosts both for oviposition (reproduction) and for food source, we then compared egg production among females when different food sources (host blood, sucrose or water only) were given. Host provision strongly affected the longevity of females. Wasp life-span was shortened when hosts had been given, suggesting the cost of reproduction in regard to oviposition. Cost of reproduction also tended to depend on the size of females; larger females suffered a greater cost. Females fed on host blood carried much more eggs than those fed on sucrose or water only. When sugar source is lacking or only water was given, they showed 'egg resorption'.
\end{abstract}

Key words: Body size, egg production, fitness, Ichneumonidae

\section{INTRODUCTION}

Theory of life-history evolution suggests the presence and importance of trade-offs among reproductive traits because they should play an important role in shaping the structure of life history (Sterns, 1989; Roff, 1992). Under the constraint of some conditions, a tradeoff may appear between two ecological or physiological traits; a positive change in one trait by itself is opposed by a negative effect in another (Jervis and Kidd, 1986; Ellers et al., 1998; Roff and Fairbairn, 2007). For example, an investment of more internal resources towards egg production may lead to a shorter life-span (Harvey, 2008). Such a relationship is often referred as to the cost of reproduction.

Parasitoids lay their eggs on or in the body of other insects, i.e., hosts, and the larvae develop by feeding on the host and eventually kill it. Parasitoids have long been excellent model organisms in testing many aspects of evolutionary theory, including life-history evolution in relation to trade-offs (Godfray, 1994). However, cost of reproduction has been examined only for a few species of parasitoids so far.

Nutrient acquisition and allocation can critically impact the fitness of parasitoids (Rivero and Casas, 1999; Jervis et al., 2008). During the immature stage, parasitoids acquire from their host nutrients that are required for their development and part of egg production in adult life (Godfray, 1994; Harvey, 2005). Adult parasitoids, particularly the females, require sources of carbohydrates, such as honey and honeydew, to support their

* Corresponding author (E-mail: ueno@grt.kyushu-u.ac.jp) daily maintenance and reproduction (Boggs, 1981; Ho and Ueno, 2011). In addition, many species of parasitoids that produce eggs throughout their adult life (i.e., synovigenic parasitoids) exhibit host-feeding behavior, and consume the host body fluids and tissues, to acquire the crucial nutrients (mainly proteins and lipids) for egg production (Jervis and Kidd, 1986; Heimpel and Collier, 1996; Ueno, 1999a). Synovigenic parasitoids typically emerge with a limited number of mature eggs and continue to mature eggs during the adult stage (Jervis et al., 2001). Thus, their fitness is strongly dependent on the number of further eggs that they can produce during their adult life (Rosenheim, 1996; Ueno, 1999a).

Body size, which directly reflects the resource acquiring and/or storing capability of an individual, is one of the key traits because it is correlated with life-history parameters such as mating efficiency, dispersal capability and most importantly, reproductive success (Ueno, 1998, 1999b; Ellers et al., 1998). Larger body size enables parasitoids to store more energy and to produce more eggs, resulting in longer life span and higher reproductive success (Ueno, 1999b; Rivero and West, 2002; Ueno and Ueno, 2005). Numerous laboratory studies have reported the positive correlation between body size and longevity or fecundity in parasitoids (Nakamura, 1995; Bezemer et al., 2005; Harvey, 2008).

Itoplectis naranyae Ashmead (Hymenoptera: Inchneumonidae) is a solitary endoparasitoid wasp that attacks a variety of lepidopterous pupae (Ueno and Tanaka, 1994). This parasitoid is widespread and abundant in rice paddies of Japan and other East Asian countries, where it is an important natural enemy of lepidopteran pests such as rice leaf folder (Ueno and Tanaka, 
1994). This species produces relatively large yolk-rich eggs throughout the lifetime (Ueno, 1998). Ueno and Ueno (2007) have demonstrated that it is typically synovigenic, and host-feeding positively affects their egg production; female I. naranyae carries no mature eggs at eclosion, but fecundity quickly increases even when hosts are unavailable. They can produce ca 30 eggs without host-feeding using nutrients stored during the larval stage. Host feeding allows females to produce additional eggs, but there is a three days' delay between the hostfeeding behavior and egg maturation (Ueno and Ueno, 2007).

Although carbohydrate food for the adults and host meal obtained via host-feeding are known to affect the fitness of pupal parasitoids like I. naranyae, it is unknown how these two nutrient sources interactively affect the reproductive success of pupal parasitoids. The present study compared the female fecundity and longevity when different food sources were given under different host availability. The reproductive strategies of synovigenic parasitoids are discussed here.

\section{MATERIALS AND METHODS}

\section{Insect culturing}

Pupae of the greater wax moth Galleria mellonella, which is wildly distributing in most of the world, were used as hosts here. Hosts were reared with an artificial diet (Ueno and Tanaka, 1994). Host cocoons containing a fresh pupa were used for the experiments. Wild Itoplectis naranyae females were collected from grassy fields on the shore of the Umigawa River, Higashi-Ku, Fukuoka City. The laboratory colony was established following the method by Ueno and Ueno (2007). Other rearing procedures were given in Ueno and Ueno (2007). All experiments in this study were carried out under controlled conditions in the laboratory $\left(20 \pm 1^{\circ} \mathrm{C}, 16: 8 \mathrm{~h}\right.$ L:D regime).

\section{Test parasitoids}

Newly emerged females for testing were collected from rearing containers $(10 \mathrm{~cm}$ in diameter, $4.5 \mathrm{~cm}$ in height) and were anesthetized with $\mathrm{CO}_{2}$ to weigh on the microbalance. The females were then individually placed in plastic containers (10 cm in diameter, $4.5 \mathrm{~cm}$ in height) together with a male. The male was removed after 24 hours.

\section{Longevity}

This experiment was conducted to estimate life expectancy of $I$. naranyae under different host and food conditions. Test females were first divided into two groups. Females of the first group were reared in the absence of host throughout their lifetime whereas, in the other group, each female was provided with 3 hosts for 2 hours every day until the death of them. Both of the two groups were further divided into two groups, and each of the groups was subject to different food type treatments: $20 \%$ honey solution and water as a control. The food source was saturated in cotton, and the cotton was replaced twice a week. Thus, in all, 6 female groups were set up and 90 individuals in all were tested. Forewing length of females was also recorded as a parameter of female size.

\section{Fecundity}

In this experiment, we designed an experimental tool to estimate egg production by female $I$. naranyae in the absence of host meal (host-feeding). Plastic tubes ( $8 \mathrm{~mm}$ in diameter) each with $40-50$ little holes $(0.3 \mathrm{~mm}$ in diameter) on the surface were prepared. A host pupa was put into each tube when given to test females. Female $I$. naranyae were able to recognize the host pupae inside the tubes and attacked them. Oviposition into host pupae was possible through the holes made on the surface of plastic tubes but feeding on host materials was prevented.

From the 3rd day after emergence, each female was offered two plastic tubes containing a fresh host pupa for 2 hours every day, and this procedure was continued in the next 9 days. Then, the saturated cotton was removed from the containers, and test females were starved for 24 hours. Twenty-four hours later, test females were orally fed $3 \mu \mathrm{L}$ different food sources (i.e., $20 \%$ sucrose solution, host blood, or water as a control) with a microinjector. Thereafter, the females were offered with water only. On the 3rd day after the treatment above, test females were dissected and the numbers of immature and mature eggs were counted under a microscope.

\section{Statistical analyses}

Statistical analyses were made with the aid of JMP (SAS Institute, 2005).

\section{RESULT AND DISCUSSION}

\section{Longevity}

The mean longevity (with \pm SE) of female wasps was $54.35 \pm 1.96$ days when no hosts had been provided while that with hosts was $45.56 \pm 0.60$ days. We applied proportional hazard fits for analyzing the longevity data. Because we had two indexes for body size, i.e., body weight at parasitoid emergence and forewing length, and

Table 1. Survival analysis for accessing factors affecting the longevity of $I$. naranyea in the absence and presence of host. Proportional hazard fits are applied

\begin{tabular}{crr}
\hline Factors & Chi-square & \multicolumn{1}{c}{$\mathrm{P}$} \\
\hline Model 1 & & \\
Forewing Length (mm) & 4.84 & 0.028 \\
Host Provision & 16.13 & 0.0001 \\
Interaction & 0.52 & 0.47 \\
Model 2 & & \\
Body Weight (g) & 1.00 & 0.32 \\
Host Provision & 14.58 & 0.0001 \\
Interaction & 1.63 & 0.19
\end{tabular}




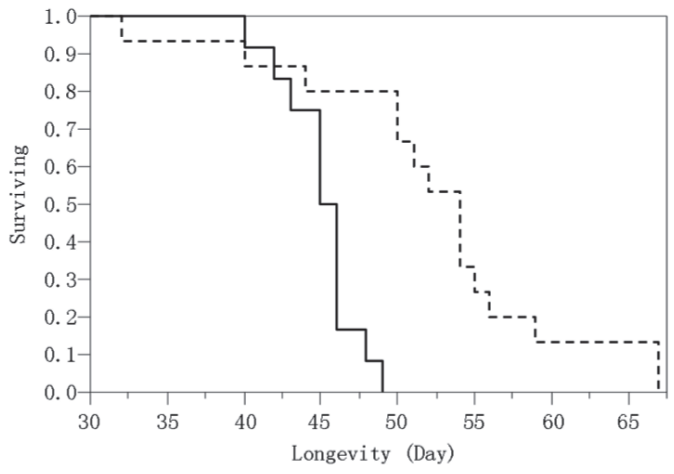

Fig. 1. The comparison of survival curves of I. naranyea between the females with hosts (-) and the ones without hosts $(---)$.

because we did not know which index was better, two models were constructed (see Table 1 ). Whole models obtained were highly significant (model $1 ; \mathrm{N}=27$, df $=3$, $x^{2}=17.82, P=0.0005$, model $2 ; \mathrm{N}=27, \mathrm{df}=3, x^{2}=15.20$, $P=0.0017)$. For both models, host provision strongly affected the life expectancy of females, and a comparison of survival curves indicated that females that had given hosts had shorter lifetime than those without hosts (Fig. 1).

Simple regression analyses were made to examine the relationships between longevity and body weight or forewing length. Forewing length was significantly and positively correlated to female longevity regardless of host presence (Fig. 2a; $\mathrm{N}=12$, df $=1, \mathrm{~F}=13.69, P=$ 0.0041 for host provided group; $\mathrm{N}=15$, $\mathrm{df}=1, \mathrm{~F}=6.22$, $P=0.027$ for host deprived group). However, body weight had a significant effect only for host provision group (Fig. 2b; $\mathrm{N}=12$, df $=1, r^{2}=0.60, \mathrm{~F}=14.93, P=$ $0.0031)$ and not for host deprived group $(\mathrm{N}=15$, df $=1$, $\left.r^{2}=0.014, \mathrm{~F}=0.18, P=0.68\right)$. Although body weight at emergence and forewing length were strongly correlated each other (Fig. 3; $\mathrm{N}=27, r^{2}=0.74, \mathrm{~F}=71.64, P=$ 0.0001 ), forewing length may be a better predictor of body size of female $I$. naranyae.

As a host-feeding species, upon finding a host, a female should face a dilemma of whether to oviposit or feed on that host. She can obtain an immediate repro-

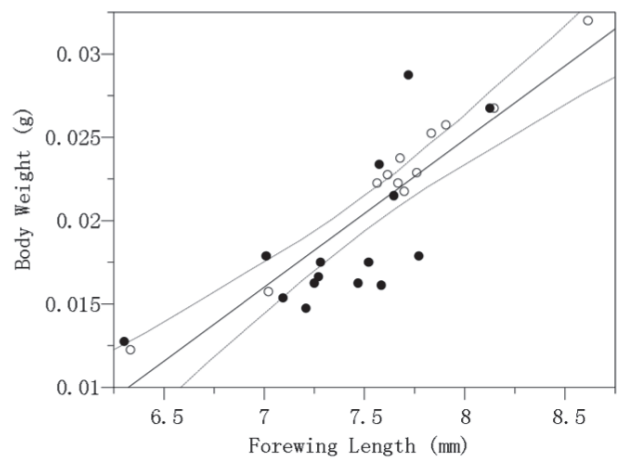

Fig. 3. The regression analyses between body weight at emergence and forewing length of $I$. naranyea. The two parameters are significantly correlated with each other.

duction success by using the host for oviposition while oviposition will decrease her life expectancy due to cost of reproduction; she can gain nutrients for future reproduction by host feeding but loses the current reproductive chance, i.e., oviposition, because host feeding causes the direct mortality of hosts, making them unsuitable for oviposition (Rivero and Casas, 1999; Giron and Casas, 2003). The differing effects of host access on longevity may be based on the strategies that parasitoids employ to obtain resources for maintenance versus reproduction (Harvey, 2005; Jervis et al., 2008). In the present study, the longevity of female Itoplectis naranyae was shorter when provided with hosts than those deprived of hosts. This finding indicates the presence of a trade-off between reproduction and life expectancy, i.e., cost of reproduction. Such a trade-off is the basis of the hypothesis of evolutionary theory of life-history (Roff and Fairbairn, 2007).

Adult parasitoid species with host-feeding behavior are highly dependent on resource acquisition from both the environment (carbohydrate and protein) and host (protein and lipid), because of the rapid depletion when resources are allocated to both metabolic activity and reproduction (Jervis et al., 2008). Carbohydrates obtained by adults from host or non-host resources enhance longevity and survival (Jervis et al., 2008). In the present study, female I. naranyae were allowed
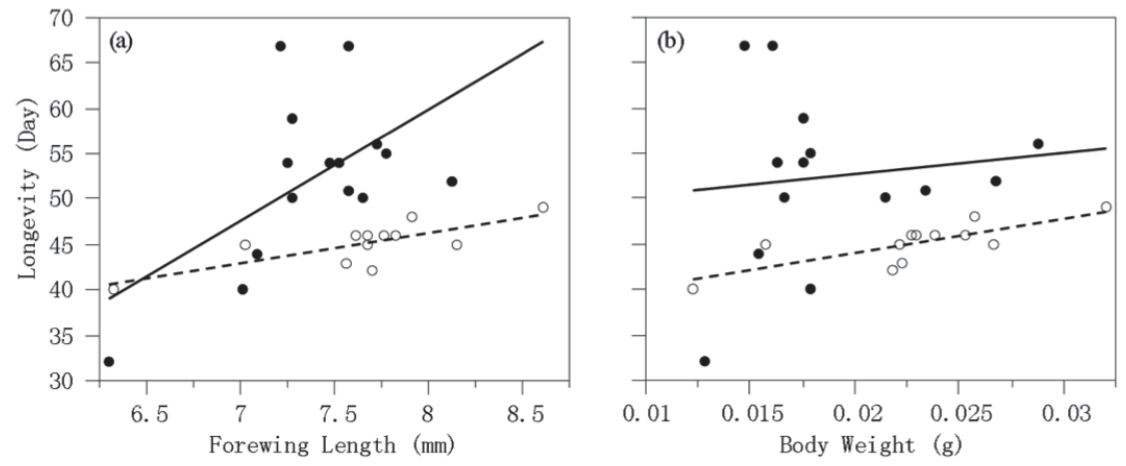

Fig. 2. Simple regression analyses between longevity and body weight (a) or forewing length (b) of $I$. naranyea. Both of them significantly affected the longevity no matter the host presence (-๑ -$)$ or host absence $(\rightarrow \bullet)$. 
unlimited access to a carbohydrate source, i.e., honey. In this experimental condition, their mean longevity is beyond 1.5 months, the value of which demonstrates a considerably long lifetime of $I$. naranyae among parasitoid wasps. Even under such a favorable condition, we have detected the cost of reproduction; if food limitation occurs, the degree of the cost may be much higher depending on the size of females. Future studies will then focus on the interaction between food and cost of reproduction.

\section{Fecundity}

The number of mature eggs that female I. naranyae carried significantly differed among the three groups (Fig. 4a; $\mathrm{F}=17.62, P=0.0001$ ). Females orally fed with host blood had the greatest number of mature eggs (mean \pm SE: $35.5 \pm 3.14)$, those fed with sucrose (31.1 \pm 2.75$)$ intermediate, and the control group carried the least number of mature eggs (27.3 \pm 3.30$)$. Curiously, the number of immature eggs did not differ among the three groups (Fig. 4b; $\mathrm{F}=0.33, P=0.7201$ ).

In general, synovigenic parasitoids produce relatively large, yolk-rich eggs, but emerge with only a small fraction of their potential egg complement and continue to mature eggs throughout the adult life (Jervis and Kidd, 1986; Ueno, 1999b). The fat body is accumulated during the larval stage and is carried over to the adult stage when it may be metabolized for egg production (Rivero et al., 2001; Bezemer et al., 2005). Recent physiological studies have given evidence that adult parasitoids can not synthesize new lipids from carbohydrates (Casas et al., 2003; Giron and Casas, 2003). Comparative studies have further suggested an absence of lipogenesis during the adult stage may exist across all Hymenoptera (Jervis et al., 2001; Jervis and Harvey, 2008). Host tissue and blood contain a rich source of nutrients useful for egg production such as protein and fats that are either scarce or absent in other foods (Jervis \& Kidd 1986; Heimpel and Collier 1996; Rivero and Casas 1999; O'Brien et al., 2004). Thus, parasitoids during the immature stage should store such nutrients by feeding on host tissue or blood and carry over the nutrients. Instead, synovigenic parasitoids can gain such nutrients by feeding on hosts. Host-feeding has been demonstrated to improve the fecundity in many parasitoids including $I$. naranyae (Jervis \& Kidd 1986; Heimpel and Collier 1996; Ueno, 1999b; Ueno and Ueno, 2007). Likewise, in the present study, test females that orally fed with host blood carried much more eggs than other groups. This result demonstrates that female $I$. naranyae produce eggs by using host blood. The mean difference between $3 \mu \mathrm{L}$ blood-fed and control females was 5.5 for mature eggs. This implies that $1 \mu \mathrm{L}$ host blood contains nutrients equivalent to 1.8 mature eggs.

Many parasitic wasps can reabsorb eggs under food limitation or in the absence of hosts, which was known as 'egg resorption' (Jervis et al., 2001). Egg resorption is frequently associated with parasitoid species that produce large, yolk-rich eggs and host-feed (Flanders, 1950; Bell and Bohm, 1975). It is believed that such parasitoids convert nutrients taken from their eggs for energy for maintenance or activity in order to increase the future reproductive opportunity. Egg resorption may particularly be advantageous for longer-lived species because flexible re-allocation of resources allows them to endure temporary severe conditions. In the present study, fecundity sharply decreased in the control group when compared with the female group fed with sucrose. This result indicates that egg resorption also takes place $I$. naranyae under food limitation. In fact, we observed abnormally formed eggs in the ovary when dissected control females. Because of accumulation of such eggs, the number of non-matured eggs did not differ among female groups.

\section{CONCLUSION}

Some studies in parasitoids have found evidence of a trade-off between reproduction and survival (Hohmann, 1989; Harvey, 2005), whereas others have not (Bai and Smith, 1993). Thus, the cost of reproduction is likely to differ among parasitoid species. Harvey (2008) found that even between related species - Lysibia nana and Gelis agilis, there is a strong divergence in reproductive biology because of the difference in life-history strategies they employ. The trade-offs among traits are constrained by different factors (Roff, 2000). In solitary parasitoid species, which often grow only marginally
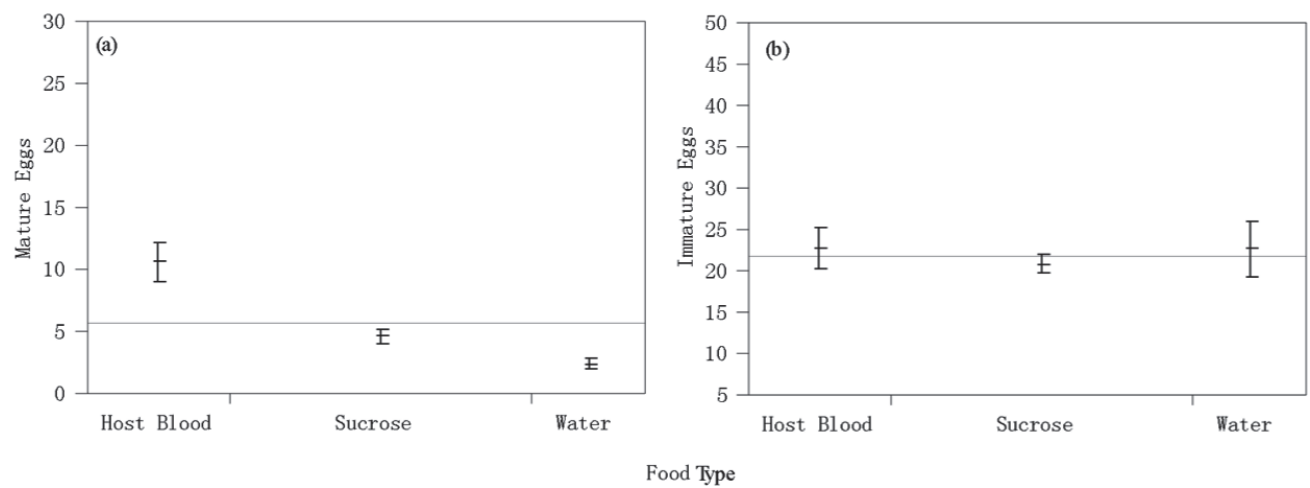

Fig. 4. The mean number of the mature eggs (a) and immature eggs (b) female $I$. naranyae carried in the ovary under three food conditions. For statistical results, see the detail in the text. 
smaller than their host, host size should limit their body size and resources they can stock (Ellers et al., 1998; Ueno, 1998, 1999b; Rivero and West, 2002; Harvey, 2005). Bcause of an absence of lipogenesis during the adult stage, constraints on lipid reserves gained during the larval stage can be a major factor influencing the reproductive strategies of parasitoids. In the present study, we have shown that female $I$. naranyae in the absence of host are able to prolong their lifetime to acquire a future reproductive opportunity, but with sufficient numbers of host, they invest to egg production at the cost of longevity. On the other side, we have given evidence that host-feeding play an important role in the egg maturation when adult nutrients is limited; when sugar source is lacking, they show 'egg resorption', which implies reallocation of resources they carry. As we have shown, $I$. naranyae has a long life span, and resource re-allocation may be advantageous for species with long lifetime because environments (host and food availability) should change temporarily during their lifetime.

\section{REFERENCES}

Bai, B. and S. M. Smith 1993 Effect of host availability on reproduction and survival of the parasitoid wasp Trichogramma minutum. Ecol. Entomol., 18: 279-286

Bell, M. J. and M. K. Bohm 1975 Oosorption in insects. Biol. Rev., 50: 373-396

Bezemer, T. M., J. A. Harvey and N. J. Mills 2005 Influence of adult nutrition on the relationship between body size and reproductive parameters in a parasitoid wasp. Ecol. Entomol, 30: $571-580$

Boggs, C. L. 1981 Nutritional and life-history determinants of resource allocation in holometabolous insects. Am. Nat., 117: 692-709

Collier, T. R., W. W. Murdoch and R. M. Nisbet 1994 Egg load and the decision to host-feed in the parasitoid Aphytis melinus. J. Anim. Ecol., 63: 299-306

Ellers, J., J. J. M. van Alphen and J. G. Sevenster 1998 A field study of size-fitness relationships in the parasitoid Asobara tabida. J. Anim. Ecol., 67: 318-324

Flanders, S. E. 1950 Regulation of ovulation and egg disposal in the parasitic Hymenoptera. Can. Entomol., 82: 134-140

Giron, D. and J. Casas 2003 Mothers reduce egg provisioning with age. Ecol. Let., 6: 273-277

Godfray, H. C. J. 1994 Parasitoids Behavioral and Evolutionary Ecology. Princeton University Press, Princeton, New Jersey

Harvey, J. A. 2005 Factors affecting the evolution of development strategies in parasitoid wasps: the importance of functional constraints and incorporating complexity. Entomol. Exp. Appl., 117: 1-13

Harvey, J. A. 2008 Comparing and contrasting development and reproductive strategies in the pupal hyperparasitoids Lysibia nana and Gelis agilis (Hymenoptera: Ichneumonidae). Evol. Ecol. 22: 153-166

Heimpel, G. E. and T. R. Collier 1996 The evolution of host-feeding behaviour in insect parasitoids. Biol. Rev., 71: 373-400

Ho, T. T. G. and T. Ueno 2011 The effects of honey as a dietary supplement on the survivorship and nutrition-storing capacity of Hemiptarsenus varicornis (Hymenoptera: Eulophidae), a parasitoid of Liriomyza (Diptera: Agromyzidae) leafminers. Int. J. Trop. Insect Sci., 31: 78-84

Hohmann, C. L., R. F. Luck, E. R. Oatman and G. R. Platner 1989 Effects of different biological factors on longevity and fecundity of Trichogramma platneri Nagarkatti (Hymenoptera:
Trichogrammatidae). An. Du. Soc. Entomol. Brasil, 18: 61-70 Jervis, M. A. and N. A. C. Kidd 1986 Host-feeding strategies in hymenopteran parasitoids. Biol. Rev., 61: 395-434

Jervis, M. A., G. E. Heimpel, P. N. Ferns, J. A. Harvey and N. A. C. Kidd 2001 Life-history strategies in parasitoid wasps: a comparative analysis of 'ovigeny'. J. Anim. Ecol., 70: 442-458

Jervis, M. A., J. Ellers and J. A. Harvey 2008 Resource acquisition, allocation, and utilization in parasitoid reproductive strategies. Ann. Rev. Entomol., 53: 361-385

Nakamura, S. 1995 Optimal clutch size for maximizing reproductive success in a parasitoid fly, Exorista japonica (Diptera: Tachinidae). Appl. Entomol. Zool., 30: 425-431

O'Brien, D. M., C. L. Boggs and M. L. Fogel 2004 Making egg from nectar: the role of life history and dietary carbon turnover in butterfly reproductive resource allocation. Oikos, 105: 279291

Rasa, O. A. E., C. Schonfled, P. Langhoff, S. Engels and A. Zielinski 2000 Benefit asymmetry in aggregations of a desert beetle: the costs of being small. Zool. Analy. Complex Sys., 103 $7-14$

Rivero, A. and J. Casas 1999 Rate of nutrient allocation to egg production in a parasitic wasp. Proc. R. Soc. Lond. B, 266: 1169 1174

Rivero, A., D. Giron and J. Casas 2001 Lifetime allocation of juvenile and adult nutritional resources to egg production in a holometabolous insect. Proc. R. Soc. Lond. B, 268: 12311237

Rivero, A. and S. A. West 2002 The physiological costs of being small in a parasitic wasp. Evol. Ecol. Res., 4: 407-420

Rivero A. and S. A. West 2005 The costs and benefits of host feeding in parasitoids. Anim. Behav., 69: 1293-1301

Roff, D. A. 1992 The Evolution of Life Histories, Theory and Analysis. Chapman \& Hall, New York

Roff, D. A. 2000 Trade-offs between growth and reproduction: analysis of the quantitative genetic evidence. J. Evol. Biol. 13: $434-445$

Roff, D. A. and D. J. Fairbairn 2007 The evolution of trade-offs: where are we? J. Evol. Biol., 20: 433-447

Rosenheim, J. A. 1996 An evolutionary argument for egg limitation. Evolution, 50: 2089-2094

Skow, C. D. and E. M. Jakob 2003 Effects of maternal body size on clutch size and egg weight in a pholcid spider (Holocnemus pluchei). J. Arachnol., 31: 305-308.

Sterns, S. C. 1989 Trade-offs in life-history evolution. Funct. Ecol., 3: 259-268

Sterns, S. C. 1992 The Evolution of Life Histories. Oxford University Press, New York

Ueno, T. 1998 Adaptiveness of sex ratio control by the pupal parasitoid Itoplectis naranyae (Hymenoptera: Ichneumonidae) in response to host size. Evol. Ecol., 12: 643-654

Ueno, T. 1999 a Host-feeding and reproduction in the parasitoid wasp Pimpla nipponica (Hymenoptera: Ichneumonidae) Inverteb. Reprod. Develop., 35: 231-237

Ueno, T. 1999b Host-size- dependent sex ratio in a parasitoid wasp. Res. Popul. Ecol., 41: 47-57

Ueno, T. and T. Tanaka 1994 Comparative biology of six polyphagous pupal endoparasitoid (Hymenoptera: Ichneumondiae): Differential host suitability and sex allocation. Ann. Entomol. Soc. Am., 87: 592-598

Ueno, K. and T. Ueno, 2005 Effect of wasp size, physiological state and prior host experience on host searching beahvior in a parasitoid wasp (Hymenoptera: Ichneumonidae). J. Ethol., 23: 43-49

Ueno, K. and T. Ueno 2007 The effects of host-feeding on synovigenic egg development in an endoparasitic wasp. Itoplectis naranyae. J. Insect Sci., 7: 46

Visser, M. E. 1994 The importance of being large: the relationship between size and fitness in females of the parasitoid Aphaereta minuta (Hymenoptera: Braconidae). J. Anim. Ecol. 63: 963-978 